warning stimulus in avoidance behavior. Journal of Comparative \& Physiological Psychology, 1955, 48, 444-450.

SIDMAN, M. Time discrimination and behavior interaction in a free operant situation. Journal of Comparative \& Physiological Psychology, 1956, 49. 469-473.

\section{Effects of the frequency of amplitude- modulated signals on the auditory evoked response}

\author{
MARTIN L. LENHARDT \\ Department of Surgery, Johns Hopkins University, Baltimore, Md. 21205
}

The relationship of the $N_{1} P_{2}$ voltage of the auditory averaged evoked response elicited by amplitude modulation has been studied. The stimuli were monaurally presented steady tones of $0.5,2.0$, and $4.0 \mathrm{kHz}$ at $60-\mathrm{dB} \mathrm{HL}$, with $10-\mathrm{dB}$ ramp modulations every $5 \mathrm{sec}$. The amplitude of the response decreased as the frequency increased.

The effects of the frequency of transient signals on the averaged auditory evoked response (AER) amplitude have been observed by Antinoro \& Skinner (1968), Evans \& Deatherage (1969), and Rothman (1970).

Generally, the data indicate a negative relationship between frequency and AER amplitude, e.g., the amplitude decreases progressively as the frequency increases. The observers are of the opinion that the AER amplitude is related to the number of neural units activated in the cochlea. Lower frequencies produce a much greater disturbance of the basilar membrane than do higher frequencies.

This hypothesis would predict that an increase in intensity of a continuous tone, which is physiologically reflected in an increased number of fibers activated, would result in a proportionally similar frequency effect. The study reported here was designed to investigate the effect of the frequency of amplitude-modulated (AM) tones on the amplitude of the averaged auditory evoked response.

\section{METHOD}

The Ss were four young adults with hearing within normal limits for the stimuli used in the study. Tones were generated by a custom-built audiometer. The continuous signals were pure tones of $0.5,2.0$, and $4.0 \mathrm{kHz}$, at an intensity of $60-\mathrm{dB} \mathrm{HL}$. At 5-sec intervals, the intensity was i n c rea sed 10 d B . The amplitude-modulated signals had a rise time of $25 \mathrm{msec}$ and a duration of $300 \mathrm{msec}$. The tones were prèsented monaurally through headphones while Ss were seated in a sound-attenuated chamber.

Electroencephalic activity was recorded from solder electrodes at vertex, referred to left mastoid with a forehead ground. Responses were summated over 70 presentations by a Nuclear Datal Enhancetron 1024 and written out by an $X-Y$ plotter. The analysis time was $4 \mathrm{sec}$. The amplitude of the first negative and second

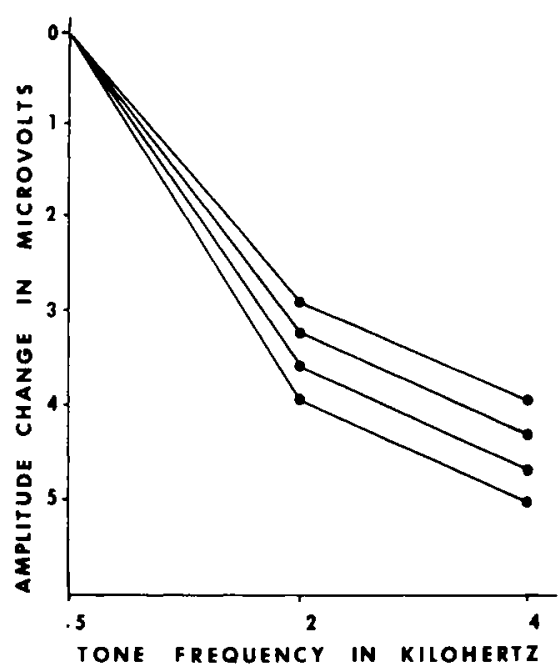

Fig. 1. Amplitude change (re $0.5-\mathrm{kHz}$ response) as a function of the frequency of amplitude modulated tones is plotted for four Ss. positive waveform peaks was measured. The decrease in voltage at 2.0 and $4.0 \mathrm{kHz}$ was assessed relative to the $0.5-\mathrm{kHz}$ amplitude.

\section{RESULTS}

The results are summarized in Fig. 1. The relative decrease in voltage is plotted as a function of frequency. The amplitude difference values averaged over the four $S$ s resulted in a mean decrease of $3.4 \mathrm{microV}$ for $2.0 \mathrm{kHz}$ and a mean decrease of $4.5 \mathrm{micro} V$ for $4.0 \mathrm{kHz}$ re: $0.5-\mathrm{kHz}$ amplitude.

\section{DISCUSSION}

A general finding that amplitude decreases as frequency increases has led to the assumption that the increased neural units stimulated by the lower frequency are responsible for the differences in the audioelectroencephalogram. A similar frequency effect was noted by $\mathrm{L}$ e n h a r t $\left(\begin{array}{lll}1971\end{array}\right)$ f or frequency-modulated tones. A tone that swept from 0.5 to $0.55 \mathrm{kHz}$ elicited a mean increase of 3.4 microV over a tone that swept from 2.0 to $2.2 \mathrm{kHz}$. The identical $N_{1} P_{2}$ voltage found in this study, using another method of stimulation (AM) within a frequency region, adds credibility to the assertion that the frequency effect is, indeed, real.

In summary, the explanation relating the increased amplitude to increased neural activity at the cochlea is applicable to transient signals of different frequencies, steady tones with frequency modulation, and steady tones with amplitude modulation. At this time, the evidence is not conclusive but suggestive. The averaging technique is still not appropriate for measuring the effect of frequency without confounding it with other parameter changes. In judging the importance of the findings, stimuli frequency, if not critical, should be low to elicit the greatest evoked signal in the background noise. Clinically, a response elicited with a low-frequency stimulus but not with a high-frequency stimulus at the same intensity may not be exclusively a result of a loss of acuity but due to the nature of the AER.

\section{REFERENCES}

ANTINORO, F., \& SKINNER, P. H. The effects of frequency on the auditory evoked response. Journal of Auditory Research, 1968, 8, 119-123.

EVANS, T. R., \& DEATHERAGE, B. H. The effect of frequency on the auditory evoked response. Psychonomic Science, $1969,15,95-96$

LENHARDT, M. L. Effects of frequency modulation on the auditory averaged evoked response. Audiology, 1971, 10 , 18-22.

ROTHMAN, H. H. Effects of high frequencies and intersubject variability on the auditory-evoked cortical response. Journal of the Acoustical Society of America, 1970, 47, 569-573. 